Move Your Money

Move your money? Sustainability Transitions in Regimes and Practices in the UK Retail Banking Sector

Gill Seyfang* and Amber Gilbert-Squires**

$3 S$ (Science, Society and Sustainability) Research Group,

School of Environmental Sciences,

University of East Anglia,

Norwich Research Park,

NR4 7TJ, UK

*corresponding author: g.seyfang@uea.ac.uk

**a.gilbertsquires@hotmail.com 


\title{
Move your money? Sustainability Transitions in Regimes and Practices in the UK Retail Banking Sector
}

\begin{abstract}
We present and test a new conceptual framework for understanding sustainable transitions in co-evolutionary sociotechnical systems. We apply this in the first study of sustainable transitions in UK retail banking. This system has suffered recently from banking crises, and links to environmentally-sensitive industries such as fossil fuels. Sustainability-focused values-based banks are a potential solution, but have had little impact on mainstream banking systems - we aim to understand the constraints and how to overcome them. Our new approach identifies the intersections between transitions in regimes (using the multilevel perspective MLP) and transitions in practices (using social practice theory SPT), two competing conceptual frameworks in the literature. We ask: what are the intersections between transitions in the banking regime and banking practices, and how may critical points of constraint be unlocked to become points of opportunity, thereby aiding a transition to more sustainable banking systems? We present new empirical findings from a mixed-method case study of the UK banking sector and two values-based banks in particular. Interventions for growing sustainable banking are identified and we demonstrate the added-value of the combined approach through indicating strategies for unlocking the transformative potential of sustainable innovations.
\end{abstract}

\section{Keywords}

sociotechnical transitions, sustainable banking, ethical banking, social practices, innovation niches

\section{Highlights}

A new conceptual framework for understanding sustainable transitions in co-evolutionary sociotechnical systems.

The first study of sustainable transitions in the UK retail banking, examining the potential for values-based banks and banking practices to grow

We identify the intersections between transitions in the banking regime and banking practices, where existing systems become locked-in

Interventions must attend to system-changes in both regimes and practices and the points where these intersect. 


\section{Introduction}

Transitions to sustainability require a fundamental shift in the way our macroeconomic banking, money and financial systems operate, yet to date this "cross-cutting distribution system" (Røpke 2017: 149) has received little attention within ecological economics. Here we aim to address that knowledge gap by presenting a novel conceptual framework for understanding co-evolutionary sociotechnical change, and applying it to the study of banking system transitions. We thereby extend and deepen current perspectives on financial system transformation.

The UK banking sector has recently suffered multiple crises and become the subject of considerable debate. The biggest (systemically-important) banks were bailed out using public funds to prevent their failure during the 2008 financial crisis (FSB, 2015), calling the sector's long-term economic stability into question. Additionally, scandals including PPI (Payment Protection Insurance) mis-selling and LIBOR (London InterBank Offered Rate) manipulation (PCBS, 2013) provoked public distrust. Campaign groups such as Global Justice, 350.org, Fossil Free UK and Move Your Money (MYM) have also raised public awareness of the banks' heavy financing of fossil fuels, weapons manufacture and financial speculation on basic commodities such as food. For UK banking to contribute to (rather than undermine) economic stability and environmental sustainability, fundamental change is required. Yet the crisis has prompted only incremental regulatory changes focused on fostering greater competition between the existing major players (BIS, 2013; HMT 2014).

Values-based banking (VBB) has emerged as a banking model that prioritises social and environmental objectives alongside profitability (UNEP, 2015; GABV 2016), and offers an innovative model with the potential to establish a more sustainable banking sector. However, the big five banking groups (Lloyds, Santander, Barclays, HSBC, RBS and their subsidiaries) maintain market dominance, and sustainable innovations have not diffused widely or achieved significant influence (CMA, 2015b).

We therefore aim to better understand how the existing banking system resists fundamental change towards sustainability, and investigate the potential of a transition toward a more sustainable UK banking sector. Specifically, we assess the scope and potential for two flagship VBBs Triodos Bank UK (hereafter Triodos) and Ecology Building Society (hereafter Ecology) to develop current accounts and increase their influence. Our proposed analytical framework brings a new perspective to bear on the subject of retail banking. It is one developed to analyse complex multi-scalar, co-evolving sociotechnical systems, bringing insights from studies of everyday practices, innovation and social change. This research offers useful insights for understanding the nature of system change required for a shift toward VBB in the retail banking sector. The multi-level perspective (MLP) and social practice theory (SPT) are two leading approaches in this field, offering distinctive insights into regime or sectoral-change and practice-change respectively (Geels and Schot, 2007; Shove 2003). In this context the MLP would understand transitions to sustainable banking as a niche innovation aiming to disrupt the existing banking system, and SPT as new elements in practices which aim to configure an emerging set of sustainable banking practices. Each perspective has valuable insights to make about the potential and barriers to systemic sustainability transitions, yet neither has yet been applied to the study of 
sustainable banking (regimes or practices). This paper provides a previously neglected empirical site to transitions research (Loorbach and Huffenreuter, 2013). However our principal aim here is to apply and test a novel conceptual approach which adopts both approaches simultaneously (developed in Hargreaves et al, 2013), and could potentially bring additional insights to the challenge of unlocking transformative innovations for sustainability. We thereby aim to extend the reach of existing literature by showing how agents of change must consider both systems and practices simultaneously in order to be effective.

Our core research questions are thus: what are the intersections between transitions in the banking regime and banking practices, and how may critical points of constraint be unlocked to become points of opportunity, thereby aiding a transition to more sustainable banking systems? To answer these questions we present new empirical findings from twin analyses of sustainable banking through MLP and SPT lenses, to learn from the ways these frameworks intersect. We use a mixed-method qualitative case study of the UK retail banking system, focusing on VBBs. We conduct semi-structured in-depth interviews with five banking experts and eleven banking service users, desk research and observation at industry events such as the Ecology Annual General Meeting. We aim to demonstrate the added-value of this combined approach through indicating the strategies it generates for unlocking the transformative potential of sustainable innovations which go beyond that suggested by existing research.

The next section outlines our theoretical contexts and new conceptual framework, and the retail banking sector which forms our case study. Methods of investigation are explained in the following section. We then present findings from our parallel investigations, of valuesbased niches and of sustainable banking proto-practices. Our integrated framework identifies critical points of intersection and constraint between sustainable transitions in regimes and practices, and we indicate how these may be transformed into points of opportunity to enable a transition to more sustainable banking. Finally, we reflect on the implications for further research, policy and practice.

\section{Theoretical Contexts}

To assess the opportunities and challenges of achieving a transition to more sustainable banking, requires an understanding of the interlocking complex, co-evolving sociotechnical systems which constitute it. Røpke (2017) takes an ecological economics perspective and defines the financial system as a 'cross-cutting distribution system', seeking to understand its influence on society's energy and material throughput within the biosphere (p.150). This promising approach specifically addresses systems which are not defined by the usual criteria of fulfilling a specific societal function (eg energy, water etc).

However, here we are seeking to grasp the dynamics of social change and innovation, and so we turn to theories of innovation in sociotechnical systems. To the extent that sustainable banking represents a radical change from the status quo, we can see these initiatives as innovative niches and novel proto-practices, and draw on theories of innovation and social change. The two bodies of literature we engage with here (the Multi-Level Perspective and 
Social Practice Theory) are the most pertinent for several reasons: theoretically, they both address the dynamics of social change and innovation, and are both gaining traction in the transitions literature; and empirically because a number of actors in the sector have been seeking radical change (transition) in the banking sector. Røpke (2017: 146) affirms that, "financial systems are constituted by both professional and everyday practices that continuously reproduce and modify their functioning, including the relevant institutions and material arrangements". Our study examines everyday banking user practices within the context of an attempted regime transition to VBB.

In section 2.1 we review the literature on innovations in regimes and discuss its relevance for the banking system. In section 2.2 we discuss social practice theories and their applicability to understanding banking practices and how these may change. In 2.3 we present our novel conceptual framework which integrates the two approaches for the first time. Last, in 2.4 we outline our empirical case of retail banking in the UK.

\subsection{Understanding transitions in regimes}

The Multi-Level Perspective (MLP) is an heuristic tool for understanding patterns and trajectories of change in socio-technical systems (defined as providing a societal function such as energy, water, housing etc and therefore combining elements such as infrastructure and institutions, users, policy and knowledge as well as technologies) (Geels 2002). The framework describes three tiered levels of increasing stability of sociotechnical configurations: landscape, regime and niche. A regime (eg the food system or transport system) comprises several inter-related dimensions such as technology, policy, law, cultures and user expectations which give the regime considerable lock-in, resilience, and stability in the face of shocks. Innovations within the regime are path-dependent, and therefore offer only incremental improvements as solutions to pressures and crises (Berkhout et al, 2004; Geels, 2010). The MLP explains processes of transition in regimes, and examines the role and potential of radical niche innovations, ie novel projects testing a fundamentally different model with the aim of disrupting incumbent sector-based regimes (see Geels and Schot, 2007; Geels, 2010), such as solar PV developing in a niche space before attempting to compete with the energy sector incumbents.

Radical niche innovations (novel socio-technical configurations) are fragile and unstable, comprising experimental projects, their networks and intermediaries, which emerge in response to perceived problems in the regime. Their success (stabilisation, diffusion and influence) depends both on factors within the niche as well as external conditions. Strategic Niche Management (SNM) examines the processes by which niches gain sufficient momentum, develop dominant designs and seize opportunities for influencing the regime. Niche innovations emerge and develop in protective spaces, shielded from competitive market pressures until they are able to compete with the dominant systems. Niche-building analyses incorporate learning, networking and visioning processes (E.g. Kemp et al., 1998). Successful learning refers to finding best practice, eg by measuring progress and sharing knowledge. Second order learning is achieved by changing wider cognitive frames. Networking relates to enrolling new actors with expertise that can contribute credibility and resources to the niche. Successful niche visioning is the articulation of clear and realistic aims which people are able to rally behind (ibid). 
The landscape level represents long term, slow-moving and deeply embedded trends that provide stability (or disruption) to a multitude of regimes. Landscape changes (eg climate change, the rise of environmentalism, wars or global recessions) put pressure on and may disrupt the incumbent regime, so opening a window of opportunity for well-developed niche innovations to intervene.

The MLP has predominantly been applied to the study of historical transitions in singlesectors such as transport and energy (Geels, 2002; Verbong et al., 2008), which have emerged from the development of niche technologies. It is increasingly applied to current and future transitions for sustainability, to inform governance interventions, eg through SNM and Transition Management (Shove and Walker, 2007, 2008). More recently, novel applications have widened its scope beyond predominantly technological innovations in the private sector, toward 'grassroots innovations' led by civil-society (Seyfang and Smith, 2007; Smith and Seyfang, 2013). Studies of social innovations include local currency systems (Seyfang and Longhurst, 2016), community energy systems (Seyfang et al, 2015) and transitions based on normative concerns such as animal welfare (Elzen et al., 2011).

The MLP is particularly relevant to a study of retail banking because the sector has a welldefined regime that has largely remained dominant despite both landscape shocks and new and attempted new entrants to the marketplace. However, to our knowledge there has been no MLP-based study of the financial system, nor of proposed sustainable solutions to it (Loorbach and Huffenreuter, 2013 is a rare exception). Yet the banking system - as a distribution system which cuts across sectoral boundaries - provides societal functions enabling economic transactions and activity. It is both similar to a number of other sectors which must undergo a substantial transition to achieve sustainability targets - eg food, energy, transport and housing systems - and even more fundamental (Røpke, 2016). Thus, the banking regime is comparable to other settings that must be considered from a transitions perspective, and our analysis of transitions in retail banking using the MLP, and our SNM analysis of values-based banking will therefore break new ground in this field and address an important research gap.

\subsection{Understanding transitions in practices}

Social Practice theory (SPT) explains how the rituals of everyday life underpin our habits, choices and actions and become shared, routinised practices. Looking beyond linear and individualistic approaches, SPT understands practices as entities that exist within selfreinforcing contexts (Evans, 2011). Practices comprise stable, shared, socially-constructed configurations of elements (such as images and meanings, skills and competencies, and material stuff). The unit of analysis is therefore the practice and individuals are carriers of practices (practitioners) (Shove, 2010). Looking at the dynamic interplay of agency and structure permits a more holistic understanding stemming from Giddens' (1984) structuration theory, and permits novel insights into how practices change over time and might transition towards more sustainable trajectories (Shove and Walker, 2010).

Established social practices are resilient to change, but they continually evolve, and can be disrupted and reconfigured in several ways, according to different levels of practices: by changing elements of practice, by disrupting and replacing existing practices, and by 
considering how practices interlock into systems of practices (Spurling et al 2013). For example, the change in social practices from bathing weekly to showering daily (which contributes to unsustainable levels of water consumption) came about through reconfigurations of the elements of bathing practices (Shove et al., 2012). Second, studies of established practices commonly focus on explaining the difficulty of replacing these with more sustainable, emerging proto-practices, focusing on domains such as bathing, clothes washing, home heating, cooking, and travelling (Schatzki, 2011). Third, there is some emerging work addressing how to change systems of connected practices (eg how exercising fundamentally links to showering, eating and washing practices) (Spurling et al., 2013). In contrast, there is relatively little research on how practice-interventions may contribute to sustainability transitions (Brand, 2010; Hargreaves, 2011; Sahakian and Wilhite, 2014; Heiskanen et al 2018 are rare examples).

Here our attention is on the potential for innovative sustainable practices to recruit practitioners, and disrupt and replace unsustainable banking practices. SPT is particularly relevant to a study of transitions in banking systems because they are a feature of people's day-to-day lives, intertwined with many other practices (shopping, working, recreation etc) into a recognisable system of practices (Spurling et al, 2013; Røpke 2017). Ours is the first study to apply SPT to existing everyday banking practices and consider the transformative potential of novel proto-practices of values-based banking. We do not address professional banking practices in this study, as we wish to focus on the everyday user's experience. We know that the majority of current account holders have not switched to a more sustainable option despite widely-recognised banking failures. We therefore seek to understand why mainstream banking practices remain robust, and to identify potential for disrupting and reconfiguring banking practices to enable sustainable system change. This research will contribute a novel understanding of the social phenomena of (not) switching banks in the UK as well as how daily money management practices influence our choice of banking institution.

\subsection{Connecting regimes and practices to understand system-change}

The MLP and SPT represent competing conceptualisations of systems and transitions, that have been "developed in mutual exclusion" (Hargreaves et al., 2013: 402; see also Shove and Walker, 2007, 2008). While the MLP takes a nested hierarchy approach for understanding increasing levels of structuration which entrench institutions and reinforce pathdependency, SPT adopts a flat ontology in which practices are interlinked and selfreinforcing. Regime transitions result from burgeoning niche innovations taking advantage of a window of opportunity, in the context of landscape pressures creating regime crises (Geels and Schot, 2007). Meanwhile transitions in practices occur when proto-practices are formed through new combinations of elements which are compelling enough to disrupt established practices and recruit practitioners (Schatzki, 2011). While fundamentally different ontologies, parallels exist between the stability of regimes and practices and possible disruption by niches and proto-practices. Both approaches offer valuable insights into system change, but each is fundamentally constrained in its understanding of systemic transitions by its exclusive sectoral or practice focus. 
Recognising that these two approaches represent complementary systemic understandings of social life and transition, Hargreaves et al. (2013) propose a new model which overcomes this limitation, in analysing socio-technical system change (adapted from Shove, 2003: 193). Without diminishing the utility of either by merging them into a single format, they examine the "interplay" (Hargreaves et al, 2013: 407) between them to better comprehend the factors locking in unsustainable regimes and practices. Transitions-in-regimes intersect with sets of practices and vice versa, and these intersections may constrain or enable transformative innovation for sustainability. Revealing these critical points of constraint (at which transitions in regimes and practices are blocked), allows us to better understand and potentially intervene to unlock the transformative potential of sustainability innovation (ibid).

The concept of regimes could be subsumed into practice theory to explain how practices are locked in, just as well as practice theory could be subsumed into the regime level of the MLP, as one of the dimensions explaining how the regime is locked in. We seek to do neither, but instead to find the interplay between, around and within the spaces in which they interact. These nuanced spaces are by their nature more complex, and may appear messy at times. But once observed, we believe they point to those spaces that are most critical for opportunity and action in managing a transition. A further reason for an MLPSPT analysis is the many interesting parallels between them. The units of analysis practices and regimes are both well-defined, largely stable and resistant to radical changes. Both go some way to understanding lock-in. Similarly, just as radical niches can disrupt and reconfigure regimes, proto-practices can disrupt and reconfigure dominant practices.

Hargreaves et al (2013) retrospectively applied this connected model to two small-scale, civil society-led case studies which had previously been studied using either the MLP or SPT, to offer further, complementary insights into system-change in each area. Few other studies have attempted to combine the approaches (McMeekin and Southerton, 2012, is a rare exception), and none have considered the banking system as a subject. The present study is therefore the first full empirical test of this new approach, and in contrast to the previous application, examines a national commercial sector that permeates everyday life.

\subsection{Empirical context: UK retail banking}

Recent banking crises, and links to environmentally-sensitive industries such as fossil fuels, suggest that to be economically, socially and environmentally sustainable, a transition in the UK banking system is required (Røpke, 2017). But the extent and nature of this change is contested. The UK government and regulatory bodies stress the importance of competition (ICB, 2011) and to this end launched the Current Account Switch Service (CASS) in September 2013 which guarantees an account switch will be completed within 7 days, without disruption to finances (HMT, 2013). Regulators are also taking action to promote competition (FSA, 2013). The Prudential Regulation Authority (PRA) and the Financial Conduct Authority (FCA) have sought to promote market entry by increasing support for bank licencing applications and lowering capital and liquidity requirements (FCA, 2014). The underlying assumption here is that greater competition will fix the banking sector; however, others believe this is insufficient for establishing sustainability. The Move Your Money (MYM) campaign and the New Economics Foundation (NEF), for example, call for 
fundamental change toward greater diversity of banking models. NEF have published numerous reports advocating alternative banking models (e.g. Prieg \& Greenham, 2014) and MYM have ranked over seventy banks and building societies using an Ethical Scorecard to encourage the public to switch banks (see MYM, 2014b).

The UK's retail banking sector is currently dominated by five major banking groups (Lloyds, Santander, Barclays, HSBC, RBS and their subsidiaries) that maintain an $85 \%$ share of the Personal Current Account (PCA) market (CMA, 2015b). The remainder comprises a variety of mainstream challenger banks (eg. Metro, Virgin and online-only services from Tesco and First Direct) and middle-ground banks such as the Cooperative (ethical investment policies) and Nationwide Building Society (member-owned) which embody some sustainable banking principles, but have also been caught up in recent banking scandals and are closer to the major banks' models.

Here we are interested in the remaining category of values-based banks, which includes a diverse range of "social, ethical, green and community banking... and includes public limited companies, mutual, and private banks." (UNEP, 2015:15). Examples include mutuallyowned building societies that focus on mortgages; credit unions offering membership based on a common bond (usually location or profession) that provide savings accounts and smallscale loans at affordable rates; cooperative banks and banks that lend exclusively to ecologically-oriented projects. The characteristics of values-based banking are:

“Economic, social and environmental performance as a 'triple bottom line'... Grounded in communities, serving the real economy... Long term relationships with clients... Long-term, self-sustaining, and resilient to outside disruptions; Transparent and inclusive governance; Culture of the bank which embeds these principles... [and] the social mission to educate and empower customers and other stakeholders to be part of a values-based economy" (ibid).

Within this sector, we examine two flagship VBBs: Triodos Bank UK (Triodos) and Ecology Building Society (Ecology). These empirical cases are selected because they are the only UK members of the Global Alliance for Banking on Values (GABV) and are the highest-scorers on MYM's ethical scorecard; they are at the cutting edge of VBB development, and they plan to offer a wider range of retail banking services. They have a focus on lending for positive impact and sustainable-housing mortgages, respectively, and both lend responsibly while maintaining relatively low loan-to-deposit ratios in order to safeguard economic resilience (Kaufer, 2011). These two VBBs were both established in 1980. Triodos originated in the Netherlands and arrived in the UK in 1995; the UK branch of Triodos has 47,014 customer accounts (Triodos, 2015; 90). Ecology operates solely in the UK with 9,000 customer accounts (Ecology, 2015). Both are members of the GABV, an international VBB movement which is an effective networking and intermediary organisation. The GABV launched in 2009 and has 46 individual bank members, operating worldwide, with combined assets of \$127billion (GABV, 2018). At the time of this research, both institutions offered only a partial banking service ie. savings and mortgages or investments and expanding into the current account market would be a significant step into becoming established as a full retail banking service. Triodos already provided a full retail banking service in the Netherlands, 
and, following ongoing announcements over multiple years that a current account service was in the pipeline, this finally became a reality in 2017 (Triodos 2018). Ecology acknowledges demand for current accounts from their members but has not made any firm commitments due to existing obstacles and risks inherent in pursuing such growth (Ecology, 2015). International comparisons between the UK and other countries with fullservice VBBs would be a fruitful avenue for future research, as would a longitudinal study of the spread of VBBs in the UK now that Triodos has launched current accounts ${ }^{1}$; however both are beyond the scope of the present paper.

Despite efforts to improve the sustainability of the banking system, significant change is elusive. Consequently our research asks how sustainability-focused VBBs can be successful in this next stage of development. We examine how analyses of banking practices and regimes, and the intersections between the two, can inform a transition toward sustainable banking systems. We therefore investigate: a) the scope and potential of VBBs as an innovative niche to influence the banking regime; b) the scope and potential of new sustainable-banking practices to recruit practitioners; and c) what a combination of these two analyses reveals about potential interventions to facilitate a transition to sustainable banking systems.

\section{Methodology}

We use a mixed-method qualitative approach to investigate sustainability transitions in a case study of the UK retail banking system. We first investigate the banking sector using an MLP framework, examining the landscape, regime and broad sustainable banking niche, to differentiate between regime and niche; we then focus specifically on VBBs to examine how that niche innovation is developing and diffusing, its intermediary actors and influence on the regime. Our primary evidence for this sector analysis is 5 semi-structured in-depth elite interviews with a diverse range of banking sector experts, including the Founder and the Campaign Manager at MYM, Triodos Bank's Head of Public Affairs and Programme Director at the GABV and a Regional Service Manager from one of the big 5 banking groups. The interview schedules were tailored to each respondent's position in the banking system, and all sought to elicit information to map out the VBB niche, the wider banking regime, and landscape pressures from their expert perspective. In particular, these questions focused on the opportunities and challenges facing VBBs, their view of public opinion on such matters, bank-switching behaviour, regulatory contexts and the development of the VBB niche within the wider banking sector in general. Contextual background information was also gathered from desk research and observation at industry events such as the Ecology AGM. Standard qualitative data analysis methods are used to code interview transcripts using MLP-theoretically-informed codes (landscape, regime, niche, diffusion and nichebuilding processes: networking, learning, visioning), and seeking patterns and frequencies of occurrences among the data. Experts are labelled E1-E5 in no particular order

\footnotetext{
${ }^{1}$ Triodos' new current account is part of the Current Account Switching Service, with access to payment systems, allows arranged mortgages and offers both online and mobile banking services (Triodos 2018)
} 
Next, we present a SPT analysis, comparing established mainstream consumer banking practices to the proto-practices of customers of sustainable banks (as several building societies and credit unions have already expanded into the Personal Current Account market, they offer useful insights for the potential expansion of VBBs into this area). Here, our data comprises in-depth semi-structured participant interviews with 11 consumer banking service users (practitioners). These were purposefully sampled for maximum diversity of sustainable banking experience. Unsurprisingly, all eleven have been mainstream bank customers. Five had not attempted sustainable banking at all, and the remaining six had experienced switching from the regime to sustainable banking niche model. Of these, two had reverted to the mainstream banks, and four continued with the sustainable bank. Only one had entirely discontinued mainstream banking.

The target audience of MYM is generally the economically active (meaning of working age, and either in or seeking formal employment) and financially mobile population, which our sample largely represented. Of eleven practitioners, eight were economically active; seven were aged 20-39 and university educated; there were seven women and four men; only one lived outside a city. The sample is therefore skewed toward younger practitioners who reside in towns or cities, for whom we assume there is the greatest scope for finding and using banking alternatives, and for whom the overdraft facility on their bank accounts is an important factor. While we are very limited in the conclusions we can draw for rural residents, our sample nevertheless allows us to make strong conclusions about the intersections between banking practices and regimes.

These SPT-informed interview schedules focused on uncovering the various practices involved in personal banking, and particularly to explore the elements of banking practices, and how VBBs and mainstream banks fit into these. Questions typically covered respondents' banking histories including opening, closing and switching banks, the banking services and functionality they valued, their account management and day-to-day banking activities, their lifestyles, attitudes and motivations and knowledge about banking, and their views of VBBs and mainstream banks. Again, interviews were transcribed and standard qualitative data analysis methods were used to code the data, in this instance, using codes derived from SPT themes (images, skills, stuff, stability of practices, reconfiguration of practices and connectedness between practices). Results have been anonymised and each interviewee assigned a code. Practitioners are labelled P1-P11, in no particular order.

\section{Findings:}

In this section we present our parallel analyses of the banking regime and banking practices. Section 4.1 adopts an MLP approach, and draws on elite interviews with actors in the mainstream banking regime and VBB banking niche to investigate potential transitions to sustainable banking by examining regime and niche dynamics in the banking sector. Section 4.2 examines existing and potentially new banking practices from the perspective of retail banking users, drawing on the evidence of our banking practitioners. 


\subsection{Regime and Niche Dynamics in the UK Banking Sector}

Within the MLP, the banking regime displays a historically high level of stability. Recently, multiple landscape pressures have revealed crises within the system which have driven incremental regime change through regulation, and provided a window of opportunity for niche banking innovations to interrupt and reconfigure the regime. Here we present a comparison between the characteristics of the UK retail banking regime and niche sustainable banking innovations. We then narrow our focus to consider VBBs in particular, and present and discuss evidence of niche-building activities and the extent of niche diffusion, to consider their potential to achieve influence in banking system transitions.

\subsubsection{Regime Analysis}

Table 1 compares the principal dimensions of the incumbent regime with an emerging proto-regime (niche) of sustainable banking innovations, according to the dimensions set out by Geels and Schot (2007). This simplified characterisation is a useful heuristic device to best grasp the key distinctions between regime and niche attributes. While not attempting to be a comprehensive depiction of a dynamic sector, nevertheless the framework serves to highlight the aspects most pertinent to our analysis. The regime is characterised by shareholder ownership which translates into a business model based on growth and profitability. A static current account market presents challenges to gaining market share (E4), and the incumbents attempt to defend market share. Crucial to maintaining this oligopoly is access to payment systems e.g. BACS, Faster Payments Service (E2). The regime prevents market entry by "erecting unnecessary barriers to direct membership of the payment systems; and failing to offer indirect access to the payment systems on fair and transparent terms" (HMT, 2013) as well as impeding innovation and competition between payment systems (ibid). The regime has come under increasing pressure from landscape trends (financial crisis of 2008 and public dissatisfaction, climate change and the divestment movement) and from crises within the regime itself (PPI misselling, LIBOR manipulation and FOREX rigging) (E4; E1; E2). However, despite widespread innovation and reform within the sector to manage such threats, regime-analysis indicates a well-entrenched sector with high levels of stability in terms of fundamental dominant power structures. This is reinforced by compatibility with other macro-level systems: retail, economic, monetary and investment in a variety of industries, and bolstered (rather than threatened) by regulatory measures (HMT 2014; Loorbach and Huffenreuter, 2013). 
Table 1: Characteristics of mainstream banking regime and sustainable banking niches

\begin{tabular}{|c|c|c|}
\hline Dimension & Banking regime & VBB niche \\
\hline $\begin{array}{l}\text { Users, } \\
\text { markets }\end{array}$ & $\begin{array}{l}\text { Money creation through extension of } \\
\text { credit; } \\
\text { Speculative investment; } \\
\text { Static Personal Current Account market }\end{array}$ & $\begin{array}{l}\text { Low lending-to-deposit ratios; } \\
\text { Responsible lending and investing; } \\
\text { Lower capacity for member deposits }\end{array}$ \\
\hline Industry & $\begin{array}{l}\text { Oligopolistic and homogenous sector; } \\
\text { Shareholder-owned; } \\
\text { Profit-maximising; } \\
\text { Control of payment systems; } \\
\text { Sunk costs; } \\
\text { Centralised decision-making }\end{array}$ & $\begin{array}{l}\text { Heterogeneous sector; } \\
\text { Member-owned, mutual and co-operative; } \\
\text { Pro-social and environmental policies; } \\
\text { Democratic decision-making; } \\
\text { GABV support network. }\end{array}$ \\
\hline Policy & $\begin{array}{l}\text { Political support; } \\
\text { FCA and PRA regulation; } \\
\text { Influential lobby; } \\
\text { Competition over diversity; } \\
\text { FSCS scheme; } \\
\text { Compliance }\end{array}$ & $\begin{array}{l}\text { FCA and PRA regulation; } \\
\text { FSCS scheme; } \\
\text { Promotes diversity of banking models and } \\
\text { competition; } \\
\text { Compliance }\end{array}$ \\
\hline Technology & $\begin{array}{l}\text { Technical infrastructure enables payment } \\
\text { system participation; } \\
\text { Centralised IT networks; } \\
\text { Professional online banking; } \\
\text { Card issuer servers; } \\
\text { mPay (mobile payments) }\end{array}$ & $\begin{array}{l}\text { Barriers to payment system and 7-day-switch } \\
\text { participation due to lack of technical } \\
\text { infrastructure and costs (indirect access is } \\
\text { not on fair \& transparent terms). }\end{array}$ \\
\hline $\begin{array}{l}\text { Science, } \\
\text { Knowledge }\end{array}$ & $\begin{array}{l}\text { Neoliberal economic perspective; } \\
\text { Debt-based banking model; } \\
\text { Informed by monetary measures of } \\
\text { growth and progress }\end{array}$ & $\begin{array}{l}\text { New economics perspective rooted in } \\
\text { understanding that banking can } \\
\text { simultaneously provide social, environmental } \\
\text { and financial benefits }\end{array}$ \\
\hline Culture & $\begin{array}{l}\text { Large shareholders are dominant } \\
\text { influence; } \\
\text { High pay ratios between highest and } \\
\text { lowest paid member of staff; } \\
\text { Bonus culture }\end{array}$ & $\begin{array}{l}\text { Equal member-influence (usually one } \\
\text { member one vote); } \\
\text { Culture of low pay ratios and bonuses; } \\
\text { Transparency and engagement with } \\
\text { customers }\end{array}$ \\
\hline Artefacts & $\begin{array}{l}\text { Debit and credit cards; } \\
\text { National network of cashpoints; } \\
\text { Branch networks; } \\
\text { Mobile phone apps }\end{array}$ & $\begin{array}{l}\text { Single branch locations or Online banking; } \\
\text { Debit cards applicable to those with PCA } \\
\text { services }\end{array}$ \\
\hline
\end{tabular}

Based on (Ryan-Collins et al., 2012; Pettifor, 2014; Prieg and Greenham, 2014; HMT, 2013; Ecology, 2015; Triodos 2015)

\subsubsection{Niche Analysis of Values-Based Banks}

The principal points of difference between the VBB niche, and the regime are around different core values, technologies, policies, governance and ideologies (see Table 1). The VBB niche has been formed as an oppositional response to the perceived unsustainability of the regime, aiming to wield influence and help transform the sector. As such, the VBB niche is currently marginal and struggling to gain much purchase on the mainstream banking regime.

The evidence of VBB niche-building activities undertaken by Triodos and Ecology suggests that the niche is developing effectively, albeit slowly (see growth data in section 2.4). Triodos and Ecology have access to significant learning opportunities through the GABV which provides an international forum for expertise-sharing (E5). This provides the niche with assistance in developing a dominant design (first-order learning) and in reframing the 
role of banking in society (second-order learning). Triodos themselves have also learned from their experience of diffusion in the Netherlands and Belgium. Again the GABV provides a forum for significant collaboration internationally, and, domestically, there is evidence of collaboration and networking with intermediary actors and other organisations which contributes to multi-niche evolvement. We also find the VBB niche articulating a realistic vision and evidencing impact, particularly in the case of Triodos which produces an online magazine, the Colour of Money, and coherently communicates its business model and progress. Thus we find significant evidence of successful niche-building activities.

However, niche diffusion through replication, upscaling and translation has been limited. There is evidence of international replication in the case of Triodos which began operations in the Netherlands and has expanded to serve Belgium and the UK. Domestically, however, Triodos and Ecology remain single institutions and it is not apparent that the VBB model is being replicated. Other ethical banks have since become established, for example Charity Bank in 2002, however this cannot be assumed to be an example of replication, particularly as the latter have independent aims and objectives.

Both Ecology and Triodos prioritise sustainable over fast paced growth in terms of customer base and upscaling. A relatively lower loan-to-deposit ratio is maintained, in keeping with economic resilience principles. This necessitates a careful balance of loans and deposits which presents a challenge to scaling-up as any influx of new deposits would need to be balanced with greater lending and investment activities which meet environmental or social impact requirements (E1; E5). Neither does this negate growth however, for example, in 2015 Ecology announced a partnership with Abundance Generation (an investmentbased crowdfunding platform for renewable energy) which will enable greater deployment of deposits.

Having only patchy development of current accounts, the VBB niche has not been fully equipped to take advantage of key opportunities created by landscape pressures. "Mass exodus" (E2) from The Cooperative Bank (traditionally considered the UK's flagship ethical bank) following reputational scandals could have been a unique opportunity for VBBs to gain market share, yet even Triodos was ill-prepared to respond quickly with a current account service. Instead, Nationwide benefited despite lower ethical credentials (MYM, 2014a). This illustrates the importance of having a dominant design ready for a window of opportunity. However, launching current account services is in itself a risk for organisations attempting measured and stable progress (Ecology, 2015) and prediction of a window of opportunity prominent enough can be difficult. Thus, we find a precarious balance between the development of a dominant design and the unpredictable nature of windows of opportunity.

An effective niche is influential in transforming, reconfiguring, reforming or substituting an existing regime (Geels \& Schot, 2007). However, our research suggests that changes in the regime have largely been incremental, e.g. ring-fencing retail from investment-banking, restricting bonuses and attempts to drive competition. The incumbent regime has retained significant lobbying power. What is more, these changes have been driven by landscape pressures rather than niche innovations. 
Clearly there has been limited niche diffusion, despite abundant niche-building activities. By contrast the customer-centric niche of challenger banks appears to be growing in scale and influence. It appears the incumbent regime is not currently concerned by competition from the VBB niche, and perhaps has more to fear from emerging new financial technologies such as blockchain and cryptocurrencies. Translation of niche ideas into the regime is severely limited. Rather, the competitive threat is felt from challenger banks, e.g. Metro and Virgin (E4). Indeed, the regime has recognised the customer-centric style of challenger banks and adapted accordingly, yet fails to acknowledge their relatively greater ethical emphasis (see MYM, 2014c). Unlike the VBB niche, the challenger banking model bears strong resemblance to the regime, which may be a contributing factor to its level of influence. Smith (2006) shows how niche innovations are subject to the paradoxical phenomena that the closer their compatibility with the regime, the more influence they are likely to have, but the weaker their ability to effect a radical innovation; we see the same process here.

\subsection{Dynamics between existing and emerging consumer banking practices}

Here we present empirical findings from our analysis of retail banking practices, drawing on interviews with banking practitioners. First we discuss existing practices and protopractices as a whole before providing a snapshot of individual elements, organised by the 'images, skills and stuff' of practices (see Table 2). We conclude with insights about establishing values-based banking proto-practices based on our findings.

Existing banking practices are highly-established as a result of coherent combinations of elements that work particularly well together, and are highly compatible with practices in other domains such as working, shopping and travelling or moving home. Above all, practitioners seek convenience in their banking practices in order to go about daily lives hassle-free and without ongoing administrative maintenance. Problems should be resolved as seamlessly as possible and without interruption to daily life. The mainstream banking system has adapted to cater for such practices through technology that enables automated transactions such as direct-debits and standing orders (skills), nationwide branches on every high street ${ }^{2}$ (stuff) and the narrative of being a long-established and safe institution for your money ${ }^{3}$ (images). Existing practices are also compatible with the time-space inflexibility of working practices. Moreover, the ability of practitioners to access credit (skills), ubiquitous cashpoints and debit cards (stuff) and advertising of credit (images) are all complementary components to shopping practices within the retail regime.

By contrast, as Table 2 shows, proto-practices related to VBBs are found to be poorly established due to incoherent combinations of elements that are less compatible with

\footnotetext{
${ }^{2}$ We acknowledge the recent and ongoing decline of branch networks, particularly in rural towns. Despite this, the presence of the biggest banks remains substantial (particularly in cities) and incomparable to the general invisibility of VBBs and other challengers.

${ }^{3}$ We found this holds true despite the 2008 financial crisis and in fact may have been reinforced by the government bail-out, even though the Financial Services Compensation Scheme (FSCS) is applied to all institutions indiscriminately.
} 
practices in other domains. We find that proto-practices are most likely to hold when practitioners prioritise social and environmental objectives ahead of profit (images), are comfortable online and telephone banking only (materials) and have less need for shorterterm credit (skills). We find that practitioners are at risk of abandoning proto-practices and reverting to existing practices. Indeed, proto-practices work best for a subset of practitioners that are so committed to alternative banking they are willing to overlook everyday inconveniences. These practitioners are willing to accept lower functionality because they support the sustainable innovation. Next we explore the individual elements of existing practices and proto-practices in more detail.

Table 2: Comparison of existing mainstream banking practices and emerging alternative banking proto-practices

\begin{tabular}{|l|l|l|} 
Element of & $\begin{array}{l}\text { Existing mainstream } \\
\text { panking practices }\end{array}$ & $\begin{array}{l}\text { Emerging VBB } \\
\text { proto-practices }\end{array}$ \\
\hline Images & $\begin{array}{l}\text { Safety, security, professionalism, } \\
\text { viability, competitiveness, loyalty linked } \\
\text { to incentives) }\end{array}$ & $\begin{array}{l}\text { Pro-social and environmental, positive } \\
\text { lending and investing, fairness and } \\
\text { transparency }\end{array}$ \\
\hline Skills & $\begin{array}{l}\text { Access to credit, perceived/actual } \\
\text { difficulty of switching, automation, } \\
\text { account-opening procedures }\end{array}$ & $\begin{array}{l}\text { Online account-opening, more saving } \\
\text { less borrowing, lack of automation }\end{array}$ \\
\hline Stuff & $\begin{array}{l}\text { Branch and cashpoint networks, easy-to- } \\
\text { navigate online platform }\end{array}$ & $\begin{array}{l}\text { Often a single-location head office } \\
\text { branch, Online platform }\end{array}$ \\
\hline Practice as a whole & $\begin{array}{l}\text { Configurations work well together to } \\
\text { maintain stability, well-embedded with } \\
\text { practices in other domains }\end{array}$ & $\begin{array}{l}\text { Fragile \& incoherent configurations } \\
\text { struggling to recruit practitioners and } \\
\text { are at risk of being abandoned }\end{array}$ \\
\hline Comments & $\begin{array}{l}\text { Interlinks with other practices, including } \\
\text { working, shopping \& mobility, } \\
\text { Significant time-space flexibility and } \\
\text { convenience }\end{array}$ & $\begin{array}{l}\text { Works well for committed individuals } \\
\text { willing to sacrifice time-space flexibility } \\
\text { and convenience in favour of values }\end{array}$ \\
\hline
\end{tabular}

\subsubsection{Images}

Existing banking practices are coloured by a particular repertoire of meanings, notably around safety, security and professionalism. Above all, practitioners want to know their money is safe (mentioned by 8 out of 11), secure and that they will receive a professional service (6 of 11), e.g.: "I know that I can go into any Lloyds branch, and I can go into any Barclays branch and I can always get cash and I have no concerns about that" (P8). As wellestablished institutions, the mainstream banks are perceived to fulfil this role. These practitioners are reassured in knowing they can always access cash regardless of unexpected situations such as losing a debit card. By contrast, concerns are raised regarding the viability and competitiveness of VBBs. Long-standing relationships with banks are the norm and practitioners are affiliated with the concept of brand loyalty ( 9 respondents mentioned this), believing it will grant them favourable terms and conditions: "if my bank wanted to offer me a mortgage... are they going to offer me a better, cos I haven't got a history with the ethical bank, would that make a difference?" (P4). 


\subsubsection{Stuff}

Artefacts such as debit cards, computers, mobile phones and card machines cater for banking practices associated with speed, freedom and flexibility. We find that a wellestablished branch infrastructure is essential for accommodating flexibility in everyday life. For most of our respondents ( 8 out of 11), a local bank branch is a non-negotiable feature as it provides a space for face-to-face problem-solving in the event of an emergency. Indeed, the prerequisite for a local branch often rules out VBBs from consideration altogether, yet when pressed, most respondents admitted to very occasional branch use. "It's [a branch] not that important but it is a kind of, I do feel a degree of security in that, should something go wrong with my account or it be emptied out or something, I can actually walk in to a branch and talk to somebody " (P5). Others are willing to forego the comfort of a branch if online technology is capable of meeting their needs, particularly as online-banking is used far more frequently. Mainstream banks cater for this by providing a fast, secure and professional service, whereas the lack of provision by VBBs can result in practitioners reverting to the mainstream (E.g. P8).

\subsubsection{Skills}

A range of skills are required both to do everyday banking , and to change banks. Switching current accounts is perceived to be arduous and time-consuming, according to most of our practitioners (7 of 11) e.g. : "...there's so many different places to change all the details. I would say the first year of changing is a bit of a nightmare..." (P8). Moreover, switching to an alternative model requires assessments of the suitability of various accounts, particularly as practitioners aim to get it right first time to avoid further switching (6 mentioned this), thus further reproducing the norm of long-term banking relationships. Practitioners who prefer to open a new current account in-branch with the assistance of a bank clerk are less likely to follow through with a switch if the process cannot be completed within a single visit (e.g. P5) or if the necessary paperwork is deemed too arduous or time consuming (e.g. P3). A good service is expected to be fully automated with functionality for Direct Debits and standing orders and most respondents ( 8 of 11) raise concerns that sustainable banks may not have the same functionality: "it's got to be something that runs smoothly, is in the background, doesn't give me unnecessary admin... " (P5). Indeed, (P8) gives such reasons for reverting to a mainstream bank following an ethics-based switch to the Co-operative Bank.

\subsubsection{Compatibility with practices in other domains}

Money-management is closely linked to consumption practices: where do we get the purchasing power to consume? What do we spend money on? Aside from employment income, results indicate that practitioners are reassured by the ability to access credit, including overdrafts, loans and credit cards. This practice is fundamentally at odds with a VBB ethos that aims to move away from traditional models of economic growth, hyperconsumption and consumer debt as part of their overriding vision and it is not uncommon for practitioners to become trapped by mainstream banking due to dependence on an overdraft facility (P1; P2; P6), being unable to switch until the debt is cleared. Thus, switching is only possible if the new institution offers an equivalent overdraft.

We find that existing practices are locked-in to the highest degree when the account offers features and benefits that are compatible with a practitioner's lifestyle (i.e. bundles of 
practices in other domains). One interviewee going travelling was drawn to a Nationwide current account because they offered a credit card free from overseas transaction fees (P7). While the current account was not a pre-requisite for a credit card application, the data suggests that practitioners prefer to keep their banking under one roof, if possible (P4). Other interviewees described the convenience of premium current accounts which remove the necessity of shopping around for products such as breakdown recovery and travel insurance, irrespective of whether this was 'financially sensible' (P6).

SPT analysis reveals that existing practices are deeply embedded in everyday lives and routines, and VBBs face the challenge of establishing proto-practices. Practice-interventions struggle to disrupt existing well-established configurations with strong links between elements, as described above. This analysis provides the basis for guiding interventions such as: reframing the role of banking in society (images), ensuring a comprehensive and user-friendly online platform (stuff) and providing transitory overdraft facilities to enable switching (skills) which may help establish VBB proto-practices. Next, we discuss the intersections that arise between the SPT and MLP analysis in order that greater contextual understanding may further refine interventions.

\section{Discussion: intersections between systems of regimes and practices}

Discussion has so far applied the MLP and SPT independently to examine the limited success of VBBs and related banking practices, respectively. We undertook these analyses with the explicit intention of applying and testing the merits of an intersections-approach in which practices and regimes intersect to reveal where systems become fundamentally locked-in, preventing successful system-innovation on either trajectory.

Each perspective reveals something about the potential and limitations of VBBs to influence wider systems. Our combined approach offers something new, and in this section we demonstrate the added value of overlaying each analysis upon the other. While both MLP and SPT offer useful insights independently, together they pinpoint the intersections that are critical for understanding where innovation in either regimes and practices meet resistance in the other, preventing niche innovations and novel practices from growing and stabilising. By identifying these critical points of intersection, we hope to generate new insights into transitions and potential for transformative change. Here we discuss the critical points of intersection at which a) transitions in regimes (through niche development) are obstructed by embedded practices and b) transitions in practices are obstructed by incumbent regimes. Our goal is to understand how to transform these points of constraint into points of opportunity, thereby informing policymakers and practitioners aiming to support sustainability transitions.

\subsection{Regime Transitions - The Added-Value of Social Practice Analysis}

Despite apparent strength in niche-building activities, VBBs have achieved only limited influence on mainstream banking. MLP analysis indicates this is due to both a highly entrenched and resilient regime, and the lack of a dominant effective niche design at the pivotal opportunity. However, our new analysis goes further to understand which elements 
of this development are most locked in to existing practices, and why they are so resistant to change. Figure 1 illustrates the added-value of applying SPT analysis to a study of regime transitions to reveal the critical points of intersection obstructing a banking sector sustainable transition. We find prominent intersections with a) banking practices $\mathrm{b}$ ) moneymanaging practices and c) switching practices, and discuss each in turn below.

Figure 1: Intersecting regimes with practices; the added value of a practice-based approach The Retail Banking System

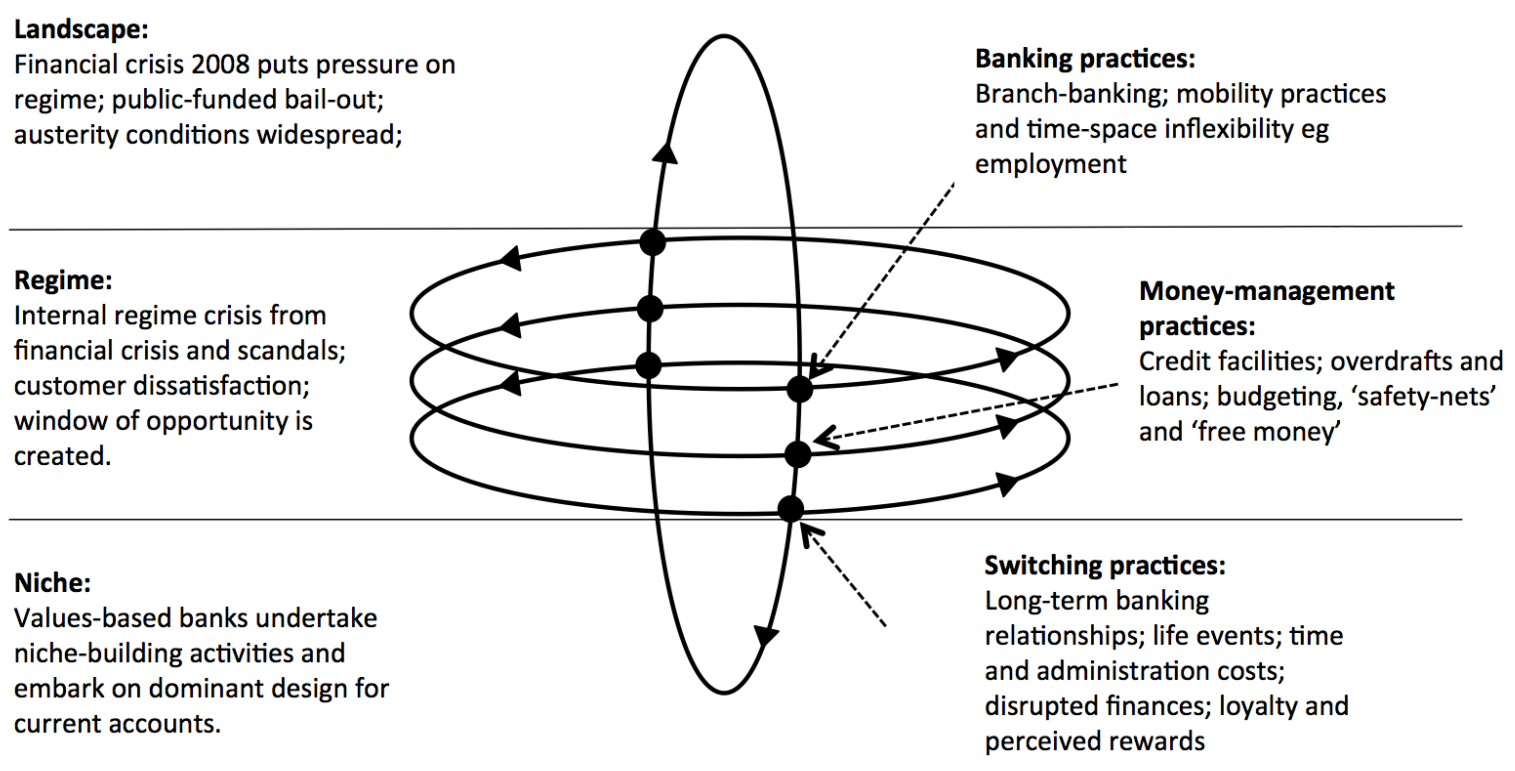

(adapted from Hargreaves et al, 2013)

\subsubsection{Intersections with Banking Practices}

Bank branches are both expensive to manage and represent values-based banks state a preference for committing money to ethical organisations rather than running costs (eg. Triodos, 2015), thus favouring online-banking This niche-regime dynamic is constrained by established banking practices that are heavily reliant on branch networks for attributes customers value highly: access, problem-solving and customers' perceptions of financial safety and tangibility. This is reinforced by lifestyles that are simultaneously highly mobile and subject to time-space inflexibilities. Moving house or changing workplace, for example, rarely necessitates a change of bank for mainstream banking practitioners, but presents logistical obstacles for VBB niche practitioners. Similarly, branch networks mean that travelling and holidaying (particularly in the UK) rarely prohibits mainstream banking practitioners from accessing their money, even in the case of a lost bank card. Further, a 
preference for opening an account in-branch means practitioners are reluctant to switch to online-only banking such as the VBB niche offers. Here a critical point of intersection is revealed between the VBB niche that would struggle to develop branch infrastructure and existing mainstream banking practices that are branch dependent. Niche innovations are locked out by existing practices.

Understanding this critical point of intersection generates insights for practitioners and policy-makers to focus action and potentially unlock systemic transformation. Here, existing banking practices must be reconfigured toward online-only VBB proto-practices to foster growth in values-based banking innovations. Fortunately, online-banking is wellsuited to mobility and flexible lifestyles, particularly in the smartphone age. Most banking practitioners actually prefer online-banking; the crux of the problem then is safety, knowing money can be accessed in emergencies, and peace-of-mind in knowing that complex or unexpected issues can be easily resolved by speaking face-to-face. Possible steps forward for values-based banking innovations therefore include: developing a comprehensive and navigable problem-solving mechanism online, providing a well-staffed and direct telephone service charged at local rates and avoiding unpopular outsourced call-centres and extensive automated options. Further, partnering with established high street institutions could provide a means for practitioners to access money in emergencies. Smartphone technology (eg. M-Pesa) could also be used for accessing cash via retailers using a dedicated app.

It is also notable that mainstream banking practitioners are accustomed to institutions that feature prominently on the high street, serving the narrative of the incumbents as established institutions (images) as well as constant visibility of the incumbents' accessibility (skills). This makes online-only VBB proto-practices difficult to establish. The critical intersection between niche growth and practices based on high street visibility suggest VBBs need to find new ways of promoting themselves, to compete with the incumbents' imagery as safe and well-established institutions. As VBBs are relatively new, they might creatively market themselves as innovative solutions to the failings of the incumbent regime's legacy culture. A simple option would also be to increase awareness of the Financial Services Compensation Scheme's applicability across the banking sector.

\subsubsection{Intersections with Money-Management Practices:}

In providing sustainable and resilient solutions to a struggling financial system, VBB niches have a low lending-to-deposit ratio; they are reluctant to provide easily available credit such as loans, credit cards and overdraft facilities. This causes tension between VBB niches and existing mainstream banking practices that are heavily shaped by access to credit. Many practitioners feel they lack adequate budgeting skills and have become dependent on credit as a month-to-month cushion. Credit facility usage ranges from the precautionary, a 'safetynet' (P10), to being joked about as 'free money' (P1). Regardless, the use of overdrafts has become prevalent, particularly as the regime competes to offer the largest and most attractive products, for example, in the student overdraft market.

This reveals a critical point of intersection between existing mainstream banking practices that are acclimatised to easy credit, and the VBB niche's lack of credit extension. Without an equivalent overdraft offer, practitioners using overdraft facilities month-to-month are 
unable to switch from regime. VBB niche innovations will struggle to recruit more practitioners if this intersection constraint is not addressed. Possible solutions include developing transitory measures such as temporary overdraft facilities. These could be supported by budgeting expertise to enable practitioners to clear month-to-month deficits permanently. While this may not initially be an attractive option for practitioners locked-in to certain patterns of consumption, the long-term future benefits can be emphasised. An alternative approach would involve VBBs enabling wider second-order learning, reframing consumption and money management altogether, away from 'consumer society' culture.

\subsubsection{Intersections with Account-Switching Practices:}

Diffusion and growth of the VBB niche is only possible if it can recruit more customers, but the research shows that banking customers are reluctant to switch banks towards more sustainable options. Customers are most likely to switch banks during a significant change of circumstance such as going to university or getting married, or due to a specific customer complaint. Otherwise, long-term banking relationships are typical. The banking regime tactic of offering attractive student overdrafts therefore proves a critical time for locking-in practitioners. Values-based banks are unable or unwilling to compete here, it therefore becomes necessary for account-switching to become common practice to encourage niche diffusion. Despite active encouragement from multiple actors, mainstream banking practitioners are resistant to switching to VBBs due to perceived demands on time, administrative capacity and fear of disrupted finances. Customer loyalty is also perceived as a factor in securing better rates on loans and mortgages within existing contexts.

Herein lies a critical point of intersection between VBB niche diffusion and existing mainstream practices of long-term banking. Possible solutions to unlock this constraint include: ensuring that account-opening procedures require minimal administration time and effort, and encouraging parents and grandparents to open VBB savings accounts for under-eighteens, taking advantage of the inertia of long-term banking practices. Practitioners often choose the same institution as their parents and such a step would certainly familiarise children with niche VBB brands. Such a step could help generate a lifetime affinity that helps diffuse VBB niche innovations. A longer-term narrative change could be to reframe the role of banks in society. The government's bailout has helped to restore faith in the regime as fail-safe institutions which values-based banking innovations must fight against alongside intermediaries such as MYM and NEF. Alternative (secondorder learning) framings could reconfigure banks as socially-responsible participants in a future sustainable society, thereby recasting both the role and responsibilities of these institutions, and increasing the moral incentives to switch.

\subsection{Social Practice Transitions: The Added-Value of Regime-Analysis}

Although VBBs and intermediaries such as MYM actively try to reconfigure banking practices, SPT analysis demonstrates the stability of mainstream practices. Using Spurling et al's (2013) framework of levels of practices, we see a high degree of connectedness between elements of practices, strong resistance to competing practices, and robust interlinkages between banking and practices in other domains, resulting in resilient systems 
of practices. However, efforts to disrupt existing practices are also hindered by lock-in with regimes; our combined analysis helps us understand which regimes contribute most to retaining existing practices. Figure 2 illustrates the added-value of applying regime-analysis to practice reconfiguration to reveal the critical points of intersection obstructing a sustainable banking transition. Here we discuss intersections with three different systems of provision: a) banking regime (providing banking services) b) retail regime (consumer provisioning services) c) economic regime (the systemic logic which serves and orients other economic services). While depicting each as a distinct regime for the purposes of analysis, all make up fundamental aspects of the banking regime as a whole; banks being a consumer service informed by economic ideas, narratives and organisational structures.

\subsubsection{Intersections with the Banking Regime}

Reconfiguring banking practices towards switching to VBBs is difficult because the incumbent regime helps maintain long-term banking practices through factors such as brand loyalty (images) and evermore customer-centric branch banking (stuff). This hinders efforts to experiment with sustainable banking proto-practices by switching to VBBs. As a response to concerns over competition and lack of customer switching, the banking industry launched the CASS in September 2013. This could have encouraged VBB protopractices of switching by removing two key barriers: administrative processes and risks of disrupted finances. However, VBBs were not in a position to develop current accounts at this time and, even if they had, multiple barriers to accessing the CASS were cited, primarily, payment system requirements.

By developing payment systems with advanced technical functionality, levels of automation in transactions and payment-making for practitioners has increased, thus contributing to robust existing mainstream banking practices and hindering efforts to experiment with VBB proto-practices. Many sustainable banks are excluded from the CASS and access to payment systems eg BACS and the Faster Payments Service which is a requirement for membership of the scheme. By controlling and limiting access to these systems (see FCA, 2014a), the incumbent regime locks-in existing mainstream practices and deters practitioners from the emerging proto-practices of switching to niche banking innovations.

This reveals a critical point of intersection between the growth of VBB proto-practices and the inaccessible technological dimensions of the banking regime which severely limit the sphere in which VBB proto-practices can become established. Regulatory measures for opening up payment system access and shielding niche innovations would enable VBB proto-practices to recruit more practitioners. This access would further assist niche innovations in catering for automated payment-making practices, thus preventing the incumbent regime from hindering VBB proto-practices. We also suggest it is critical for government to nurture a space for innovation and competition in UK payment systems, particularly if the VBB niche simultaneously promotes online-banking; automated payment systems being necessary for online functionality.

\subsubsection{Intersections with the Retail Regime}

In the previous section, we discussed how VBB niche diffusion is difficult to achieve in the context of existing practices that preference access to credit. Here we find a further, and 
related, critical point of intersection in which the retail regime locks-in existing mainstream banking practices through driving consumption and thus prohibits experimentation with proto-practices that involve reducing consumption (stuff), living within your means (images) and budgeting (skills). Existing mainstream banking practices are locked-in by a retail regime comprising shopping spaces that drive advertising, in-built obsolescence and product upgrades, thus raising consumption and dependency on credit from incumbent banks. This makes proto-practices of saving and reducing household debt levels, difficult to establish. Possible solutions include: constructing new narratives that promote a culture of self-sufficiency and finding alternative methods for meeting universal human needs, for example, through the sharing economy and collaborative consumption. Though inevitably a long-term solution, this may contribute to reducing the over-consumption which heightens consumer dependency on credit encouraged by the incumbent retail regime.

Shopping spaces predominantly accept automated payments via VISA and MasterCard. These are the largest payment processing networks in the UK and, similarly to payment systems, are limited to the incumbent regime as niches are locked-out by unaffordable costs and technical requirements. It is difficult for merchants and businesses to choose alternative networks despite frequent complaints, eg. Worldpay requested the Competition and Markets Authority (CMA) to investigate fees charged by VISA to merchants in September 2014 but the case was dropped within 3 months on the grounds of administrative priorities (CMA, 2015a). Thus, the retail regime locks-in existing moneymanaging practices that depend on the incumbent banks and locks-out VBB proto-practices. Again, this points toward regulatory intervention for opening up access to payment processing networks as well as promotion of innovation and competition in the sector.

\subsubsection{Intersections with the Economic Regime}

While the banking regime has constrained existing mainstream banking practices to within the regime, VBBs and intermediaries such as MYM attempt to encourage switching to establish proto-practices based on social and environmental values. However, existing practices of mainstream banking based on private and financial returns and the societal functions this system provides have become entrenched by an economic regime with an overriding narrative that prioritises economic growth and profit-maximisation. While VBB proto-practices recruit practitioners on the basis of images and meanings relating to transparency, ethical lending and democratic decision-making, incumbents appeal to their customers through promises of excellent customer service and financial return. The latter is strengthened by decades of discourse on economic growth as the primary goal.

Indeed, the ideology of the current economic regime is pervasive throughout society, for example, economic education tends to be grounded in a neoliberal, rather than an ecological or new economics perspective. We are encouraged to make money by participating in the labour market rather than seeking out methods for greater self-sufficiency. Thus we find a critical point of intersection between VBB proto-practices based on social and environmental return, and a capitalist system that values profiteering.

Possible solutions include VBBs playing a role in social learning, to reframe economics toward new and ecological economic perspectives. This could be achieved by partnering 
with actors working to redefine how we measure economic progress through research, engagement and education. Indeed, to some extent niche innovations are doing this already, rethinking the role of banks in society through second-order learning and public engagement. There is certainly further scope for changing the meanings of banking, economic growth and finance in rethinking economics and shaping the future landscape of society.

Figure 2 Intersecting practices with regimes; the added value of a regimes-based approach

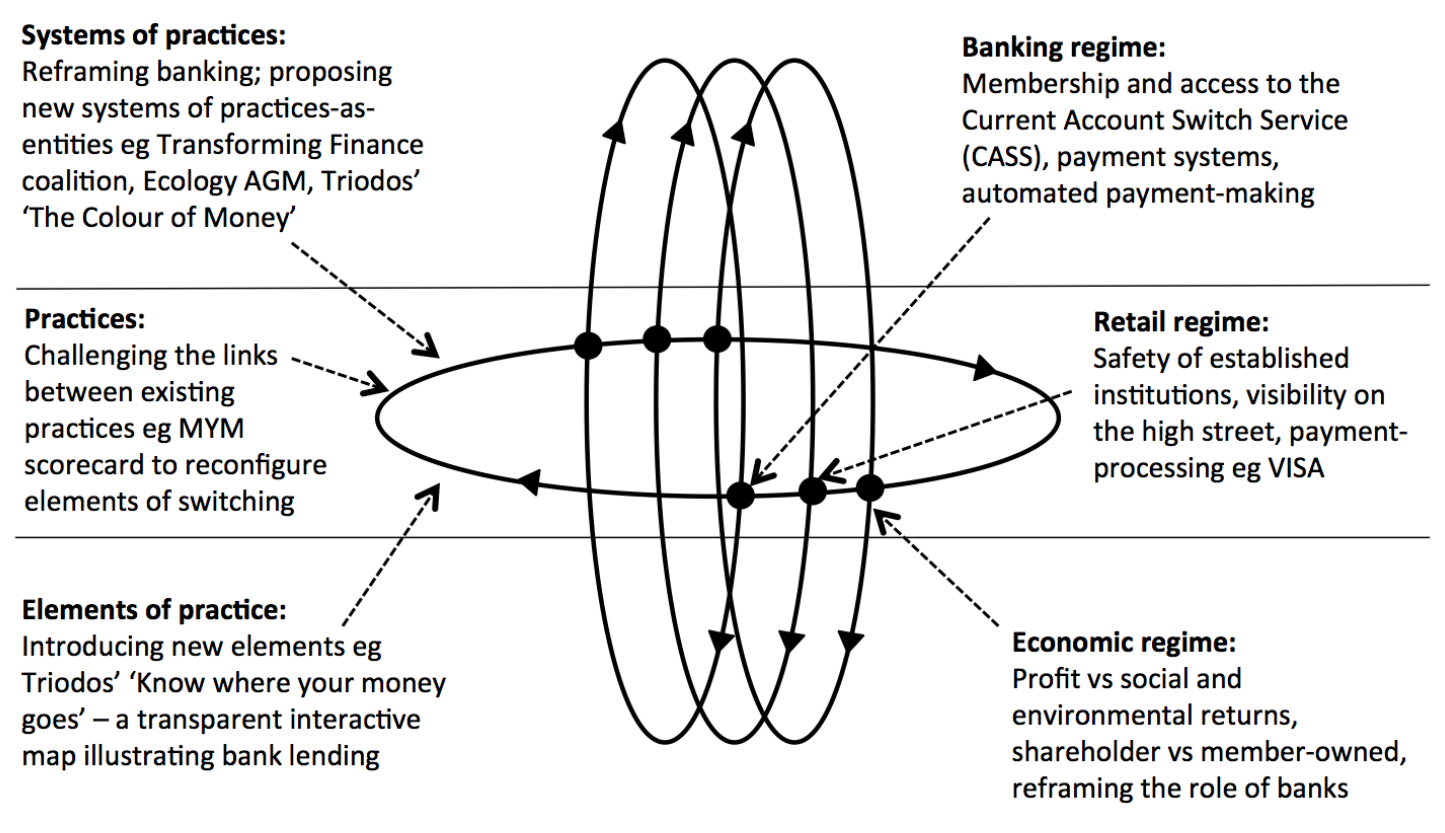

(adapted from Hargreaves et al., 2013)

\section{Conclusions}

This paper has presented new empirical research findings from a novel analysis using the MLP and SPT and is, to our knowledge, the first empirical application of a novel combined conceptual framework to understanding sustainable banking transitions. We therefore present this work as a proof-of-concept of the theoretical model, an intersections approach which extends the usefulness of both theoretical approaches and provides greater insight into understanding sustainability transitions. We have demonstrated the added value of our contribution - a combined regimes and practices analysis which shows how the critical 
points of intersection which lock-in existing unsustainable systems can be identified, and potentially transformed into points of opportunity.

These insights demonstrate the limited nature of employing only a single analysis in either regimes or practices. While existing studies of economic geography or political economy might point to interventions along similar lines to those we have identified, they are limited by a partial understanding of the systemic problem. Without a combined application of practice and regime-analyses, attempts to establish VBB niches and proto-practices are likely to achieve only limited success; following an initial period of accelerated change induced by committed activists, they may stagnate, or at worst decline, as regimes deny additional manoeuvre and practitioners revert to the convenience of existing practices. This is the pattern commonly seen in sustainability-oriented interventions, and it is time to ask searching questions about why those theoretically-informed actions are ultimately so limited. Our study here shows how it is imperative that the intersections - where they form critical points of constraint between regimes and practices - are addressed. Combined, our twin analyses reveal specific areas for targeted intervention and thus has significant implications for unlocking sustainability transitions for both policymakers and practitioners. Agents of change must, therefore, consider both systems and practices, and the intersections between the two, when designing interventions for system transitions.

Furthermore, in demonstrating the added value of an intersections approach, we equip researchers in the field with an important tool for examining sustainability transitions and open up a strand of research that focuses on the simultaneous examination of twin frameworks. It is imperative that this approach is now applied to further empirical sites, and particularly to sites that enable an analysis-in-transition approach to evaluate the outcomes of these targeted 'intersection' interventions. Empirically, we note the previous absence of banking, or indeed finance, from transitions research and urge for this strand of research to be taken up more thoroughly, as one that deeply impacts on the sustainability of multiple systems.

We do not suggest that we have exhausted the field of opportunity for targeted intervention in transitions toward sustainable banking. Rather, we demonstrate a prerequisite line of inquiry for deducing effective solutions. Questions remain around this practical outcome of our research, i.e. the targeted interventions, and further research is required to examine which combination of targeted interventions is likely to produce the most effective results? Who is best placed to enact interventions: niche innovators, regimes or practitioners? What is the sphere of influence of each? Further research unpicking the nuances of how the MLP and SPT interact is also required and we hope that our novel conceptual framework will provide the groundwork for new research on the potential of targeted intersectioninterventions to unlock the wider potential of sustainable innovations. 


\section{Acknowledgements}

The authors wish to thank all the participants in this research, and the anonymous referees for constructive comments on a previous version of this paper.

\section{References}

Berkhout, F, A Smith and A Stirling (2004), "Socio-technical regimes and transition contexts", in B Elzen, F W Geels and K Green (editors), System Innovation and the Transition to Sustainability (Edward Elgar, Cheltenham).

BIS. (2013). 2010 to 2015 government policy: bank regulation. Retrieved February 9, 2016, from https://www.gov.uk/government/publications/2010-to-2015-governmentpolicy-bank-regulation/2010-to-2015-government-policy-bank-regulation

Brand, K-W (2010), "Social Practices and Sustainable Consumption", in M Gross and H Heinrichs (editors), Environmental Sociology (Springer, Dordrecht) pp217-236.

CMA (Competition and Markets Authority (2015a). Interchange fees - MasterCard and Visa. Retrieved May 31, 2016, from https://www.gov.uk/cma-cases/investigation-intointerchange-fees-mastercard-visa-mifs

CMA (Competition and Markets Authority) (2015b). Retail banking market investigation: Summary of provisional findings report. Retrieved February 9, 2016, from https://www.gov.uk/government/uploads/system/uploads/attachment_data/file/4 70032/Banking_summary_of_PFs.pdf

Ecology (2015). Ecology Building Society Annual General Meeting (AGM): Remaking money: Transforming Finance for people and planet. April 25, 2015, Arena and Convention Centre (ACC), Liverpool.

Elzen, B, F W Geels, C Leeuwis and B van Mierlo (2011), "Normative contestation in transitions 'in the making' ", Research Policy, 40(2), pp263-275.

Evans, D (2011), "Blaming the consumer -- once again ", Critical Public Health, 21(4), pp429-440.

FCA. (2014). A review of requirements for firms entering into or expanding in the banking sector: one year on. (Prudential Regulation Authority and Financial Conduct Authority, London)

FCA (2014a), A new regulatory framework for payment systems in the UK. (Financial Conduct Authority, London).

FSA (2013), A review of requirements for firms entering into or expanding in the banking sector. (Financial Services Authority, London)

FSB. (2015). 2015 Update of List of Global Systemically Important Banks. Retrieved 31 May, 2016, from http://www.fsb.org/wp-content/uploads/2015-update-of-list-of-globalsystemically-important-banks-G-SIBs.pdf 
GABV (Global Alliance for Banking on Values) (2016) Real Economy - Real Returns: A continuing business case for Sustainability-focused Banking (GABV, Zeist, The Netherlands)

GABV (Global Alliance for Banking on Values) (2018) Banks Retrieved February 1, 2018, from http://www.gabv.org/the-community/members/banks

Geels, F W (2002), "Technological transitions as evolutionary reconfiguration processes: a multi-level perspective and a case-study", Research Policy, 31(8-9), pp1257-1274.

Geels, F W (2010), "Ontologies, socio-technical transitions (to sustainability), and the multi-level perspective", Research Policy, 39(4), pp495-510.

Geels, F. W., \& Schot, J. (2007). Typology of sociotechnical transition pathways. Research Policy, 36(3), 399-417

Giddens, A (1984), The constitution of society: Outline of the theory of structuration. (Polity Press, Cambridge).

Hargreaves, T (2011), "Practice-ing behaviour change: Applying social practice theory to pro-environmental behaviour change", Journal of Consumer Culture, 11(1), pp7999.

Hargreaves, T, N Longhurst and G Seyfang (2013), "Up, down, round and round: connecting regimes and practices in innovation for sustainability", Environment and Planning A, 45(2), pp402-420.

Hargreaves, T., Longhurst, N., \& Seyfang, G. (2013). Up, down, round and round: connecting regimes and practices in innovation for sustainability. Environment and Planning A, 45(2), 402-420

Heiskanen, E., Laakso, S., Matschoss, K. J., Backhaus, J., Goggins, G. and Vadovics, E. (2018) 'Designing Real-World Laboratories for the Reduction of Residential Energy Use: Articulating Theories of Change' Gaia, 27(S1) pp. 60-67

HMT (2013), The Regulation of Payments Networks, Summary: Intervention and Options Impact Assessment (HMT; London).

HMT (2014). Bank Reform Act 2013. (Department for Business, Innovation and Skills, London).

ICB. (2011). The Independent Commission on Banking: The Vickers Report. Retrieved February 9, 2016, from http://www.parliament.uk/business/publications/research/briefingpapers/SN06171/the-independent-commission-on-banking-the-vickers-report-theparliamentary-commission-on-banking-standards

Kaufer, K (2011), Banking as if Society Mattered: The Case of Triodos Bank (MIT Community Innovators Lab, Cambridge MA)

Kemp, R, J Schot and R Hoogma (1998), "Regime shifts to sustainability through processes of niche formation: The approach of strategic niche management", Technology Analysis \& Strategic Management, 10(2), pp175-198. 
Loorbach, D. A., and Huffenreuter, R. L. (2013). Exploring the economic crisis from a transition management perspective. Environmental Innovation and Societal Transitions, 6, 35-46.

McMeekin, A and D Southerton (2012), "Sustainability transitions and final consumption: practices and socio-technical systems", Technology Analysis \& Strategic Management, 24(4), pp345-361.

MYM (2014a), "Reaction to Nationwide's 420,000 new current accounts", available at <http://moveyourmoney.org.uk/news/reaction-to-nationwides-420000-newcurrent-accounts/>, last accessed 07/08/14.

MYM (2014c), "Metrobank", available at <http://moveyourmoney.org.uk/bank/metrobank/>, last accessed 04/08/14.

MYM. (2014b). The Move Your Money Bank Ranking Scorecard - Move Your Money. Retrieved February 12, 2016, from http://moveyourmoney.org.uk/scorecardexplained/

PCBS (Parliamentary Commission on Banking Standards) (UK). (2013). Changing banking for good. Commission Paper. (Stationery Office, London)

Pettifor, A. (2014), Just Money: How Society Can Break the Despotic Power of Finance. (Commonwealth Publishing, Margate).

Prieg, L., \& Greenham, T. (2014). Credit Unions: International Evidence. (New Economics Foundation, London).

Røpke, I. (2016) 'Complementary system perspectives in ecological macroeconomics - the example of transition investments during the crisis' Ecological Economics Vol 121 pp237-245

Røpke, I. (2017) 'Finance: An emerging issue in sustainable consumption research' in Cohen, M., Brown, H. and Vergragt, P. (eds) Social Change and the Coming of PostConsumer Society: Theoretical Advances and Policy Implications (London: Taylor and Francis) pp.145-169

Ryan-Collins, J, T Greenham, R Werner and A Jackson (2012), Where Does Money Come From? (New Economics Foundation, London).

Sahakian, M and H Wilhite (2014), "Making practice theory practicable", Journal of Consumer Culture, 14(1), pp25-44.

Schatzki, T (2011). "Where the Action Is (On Large Social Phenomena Such as Sociotechnical Regimes)". (Sustainable Practices Research Group). Retrieved 31 May, 2016, from http://www.sprg.ac.uk/publications-amppresentations/discussion-papers/schatzki-practice-theory-macro-phenomenasociotechnical-regimes

Seyfang, G. and Longhurst, N. (2016) 'What influences Diffusion of Grassroots Innovations? Investigating community currency niches' Technology Analysis and Strategic Management 28(1) 1-23

Seyfang, G., \& Smith, A. (2007). Grassroots innovations for sustainable development: Towards a new research and policy agenda. Environmental Politics, 16(4), 584-603. 
Seyfang, G., Hielscher, S., Hargreaves, T., Martiskainen, M. and Smith, A. (2014) 'A Grassroots Sustainable Energy Niche? Reflections on community energy case studies' Environmental Innovation and Societal Transitions Vol 13 pp.21-44

Shove, E (2010), "Beyond the ABC: Climate Change Policy and Theories of Social Change", Environment and Planning A, 42(6), pp1273-1285.

Shove, E and G Walker (2007), "CAUTION! Transitions ahead: politics, practice, and sustainable transition management", Environment and Planning A, 39(4), pp763770.

Shove, E and G Walker (2008), "Transition management and the politics of shape shifting", Environment and Planning A, 40(4), pp1012-1014.

Shove, E and G Walker (2010), "Governing transitions in the sustainability of everyday life", Research Policy, 39(4), pp471-476.

Shove, E, M Pantzar and M Watson (2012), The Dynamics of Social Practice: Everyday life and how it changes (Sage, London).

Shove, E. (2003). Comfort, Cleanliness and Convenience: the Social Organization of Normality. (Berg, Oxford)

Smith, A (2006), "Green niches in sustainable development: The case of organic food in the United Kingdom", Environment and Planning C: Government and Policy, 24(3), pp439-458.

Smith, A. and Seyfang, G. (2013) 'Constructing Grassroots Innovations for Sustainability' editorial to special issue on grassroots innovations, Global Environmental Change 23(5) 827-829

Spurling, N, A McMeekin, E Shove, D Southerton and D Welch (2013), Interventions in practice: re-framing policy approaches to consumer behaviour (Sustainable Practices Research Group, www.sprg.ac.uk)

Triodos. (2015). Triodos Bank Annual Report 2014. (Triodos, Zeist, the Netherlands)

Triodos. (2018). Triodos Bank Annual Report 2017. (Triodos, Zeist, the Netherlands)

Triodos. (2016). FAQs: Do you offer a current account for personal customers? Retrieved February 9, 2016, from

https://www.triodos.co.uk/en/personal/service/faq/?faqId=131865

UNEP (2015) Values Based Banking: Bringing the voice of the citizen into finance (Geneva, Inquiry: Design of a Sustainable Finance System)

Verbong, G, F W Geels and R Raven (2008), "Multi-niche analysis of dynamics and policies in Dutch renewable energy innovation journeys (1970-2006) ", Technology Analysis \& Strategic Management, 20(5), pp555-573. 